\title{
Grating Writing in Structured Optical Fibers
}

\author{
John CANNING ${ }^{1}$, Nathaniel GROOTHOFF ${ }^{1}$, Kevin COOK $^{1}$, Michael STEVENSON ${ }^{1}$, \\ John HOLDSWORTH ${ }^{2}$, Matthieu LANCRY ${ }^{3}$, and Bertrand POUMELLEC ${ }^{3}$
}

\author{
${ }^{1}$ Interdisciplinary Photonics Laboratories (iPL), School of Chemistry, University of Sydney, Sydney, NSW, 2006, \\ Australia \\ ${ }^{2}$ School of Mathematical and Physical Sciences, University of Newcastle, Callaghan 2308 NSW Australia \\ ${ }^{3}$ Institut de Chimie Moléculaire et des Matériaux d'Orsay, UMR CNRS-UPS 8182, Université de Paris Sud 11, Bâtiment \\ 410, 91405 Orsay, France
}

*Corresponding author: John CANNINGＥ-mail: john.canning@sydney.edu.au

\begin{abstract}
Grating writing in structured optical fibers is reviewed. Various laser sources have been used including UV and near IR nanosecond and femtosecond lasers, each enabling different material processing regimes. The issue of scattering is modeled through simulation and compared with experiment. Good agreement has been established.
\end{abstract}

Keywords: Gratings, structured optical fibers, Fresnel fibers, photonic crystal fibers, microstructured optical fibers, sensors

\section{Introduction}

Recent progress has been made in resolving some key issues with regards to grating writing in structured optical fibers including photonic crystal fibers [1], Fresnel fibers [2], and simple structured fibers [3] such as air clad fibers [4]. These issues are summarised as follows:

1)Rotational variation in light reaching the core as a result of variations in scattering from the structure.

2)Grating writing in non-photosensitive glasses.

3)Application of femtosecond lasers.

Each is examined separately.

\section{Rotationally variant scattering}

Scattering of the writing light from the structured cladding gives rise to a variation in light reaching the core. This is caused by scattered incoherent light and the constructive and destructive interference of coherent light scattered off all the various interfaces reaching the core. As a result the amplitude varies across the core. Such effects have been used to create filter devices based on side scattered light [5] and optical encryption [6].

Several approaches have been taken to overcome this problem for grating writing. For example, the holes can be filled with index-matching liquids for efficient coupling to the core [7-9] or the fiber can be hydrogen-loaded to increase photosensitivity and reduce the cumulative fluence [10-13]. In recent work we reported grating writing in a 12-ring nonlinear photonic crystal fiber with a highly photosensitive germanium-doped core [13, 14] shown in Fig. 1. Type IIa grating formation was observed with strengths of up to $17 \mathrm{~dB}$ in transmission. We have also carried out a detailed study of the dependence of grating writing on the

Received: 9 August 2010 / Revised version: 27 August 2010

(C) The Author(s) 2010.This article is published with open access at Springerlink.com 
angular orientation of the fiber [15-17]. In other work, we reported how the control of rotational incidence can be used to tune an induced birefringence within this fiber [18]. This birefringence arises from both incoherent scattering and coherent constructive and destructive interference within the core. Birefringence in excess of $10^{-4}$ is demonstrated - Fig. 2 summarises the observed splitting in grating spectra obtained at $21.5^{\circ}$. The angular dependence of the writing process for this fiber was supported by simulation, including an expected asymmetric intensity profile in the photosensitive region at this angle.
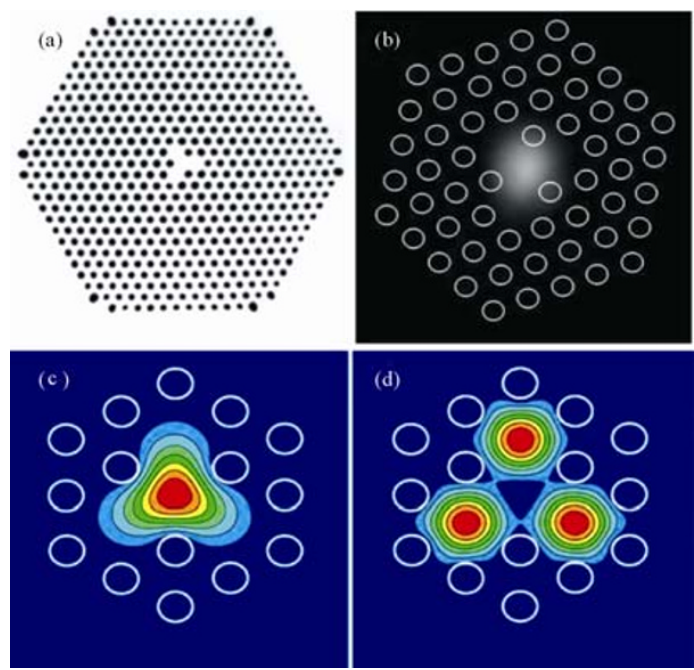

Fig. 1 (a) SEM of highly nonlinear PCF, (b) imaged mode after splicing, (c) simulated profile of the fundamental $\mathrm{TEM}_{00}$ mode, and (d) simulated profile of the higher-order TEM $\mathrm{Cl}_{01}$ mode.

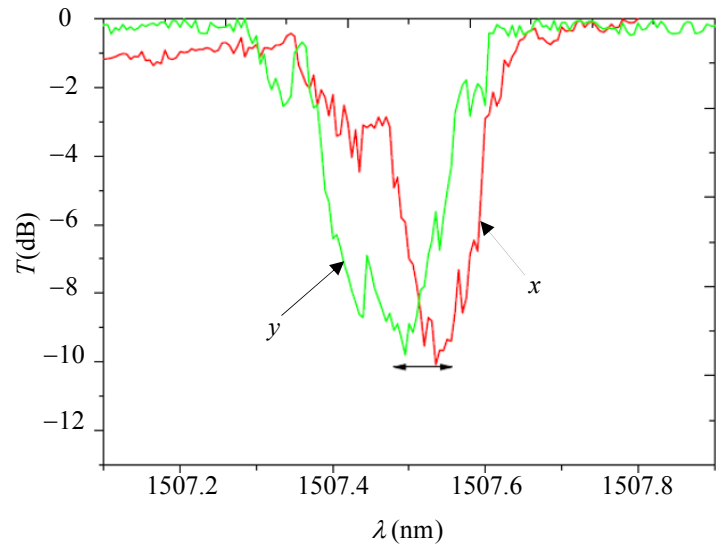

Fig. 2 Transmission spectrum for $21.5^{\circ}$ grating for two orthogonal polarisation states.
Overall, the angular dependence greatly affects the reproducibility of grating writing process within structured fibers. Therefore, good control is important to ensure reproducible access to the core by the applied optical fields - however, much more difficult to control is the sensitivity to the interference that can lead to asymmetric index changes in the core and as well affects the reproducibility of fringe contrast regardless of the total intensity in the field.

When the writing intensity is very high, two photon processes can occur with a contribution different to that triggered through defect excitation, effectively complicating grating writing in germanosilicate core fibers. Indeed, the nonlinear relation between excitation energy and index change can be exploited to produce a grating with better fringe contrast than the single photon case. This coupling into the band edge of glass can be independent of dopants. Higher intensities partially address the problem of scattering from the structured cladding to enable conventional grating writing with appropriate orientation focusing of light can occur to make up for the scattered light such that two or more photon processes are possible, discussed next.

\section{Grating writing in non-photosensitive glasses}

There are many reasons why one needs to write in non-photosensitive cores within structured optical fibers. Perhaps the most important thing is to ensure the value obtained by having a single material fiber for many applications available. This includes optimised mode field overlapped with the holes for sensing and laser applications, as well, for gratings that will not have a dependence on the properties of more than one material, such as the temperature insensitive properties of a birefringent photonic crystal fiber $[19,20]$. This problem was firstly solved using two $193 \mathrm{~nm}$ photon absorption directly into the band edge of the glass [21]. In 
aluminosilicate optical fiber, the threshold was significantly reduced whilst the total change was increased enabling the first structured fiber lasers made with gratings [22-24]. The two photon nature was confirmed experimentally $[25,26]$. It should be noted that the long cumulative fluences must ensure that these gratings are not type II damage gratings but instead densification gratings, as demonstrated in Fig. 3 and as well recent experiments based on freezing water within the holes where corrugations from densification prevent ice expansion along the channels [27].

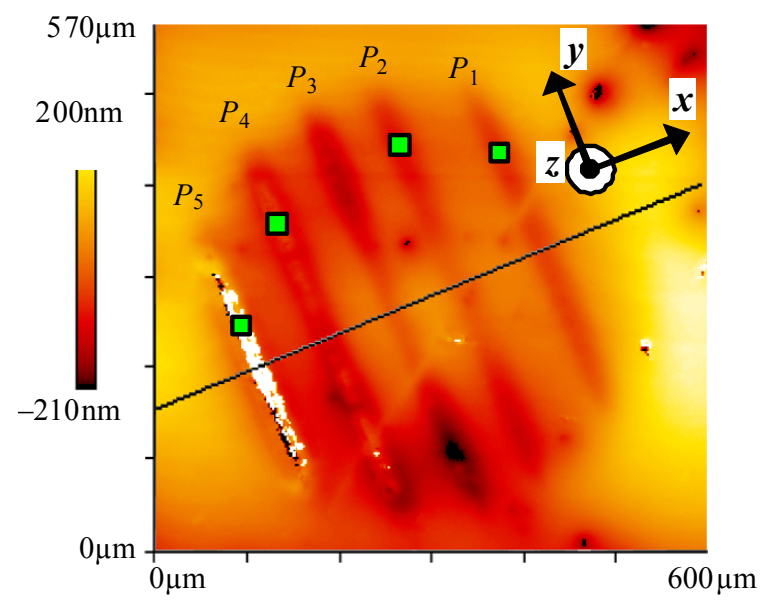

Fig. 3 Phase shift interferometric microscope image. Corrugated regions of densified glass can be seen.

\section{Application of femtosecond lasers}

Possible densification gratings have been recently reported using femtosecond gratings [28]. However the main region of interest justifying the use of these lasers is the Type II regime since changes in this regime are significantly more stable, up to $1000{ }^{\circ} \mathrm{C}[29,30]$. Type II gratings written by using energies above $T 2$ damage threshold [31] of the glass lead to very stable gratings. Normal Type I gratings are thermally annealed at low temperatures and have not been able to be incorporated within the active medium of fiber lasers for operation above $14 \mathrm{~W}[8,9,32]$. These results in an air clad structured fiber led to work on with femtosecond gratings within our group. By using liquid filling of the holes of an air clad fiber we were able to inscribe femtosecond grating directly into the core for intra cavity lasing [8, 9]. Without using the index matching gel several practical problems arose 1) alignment through an optical microscope was not possible to ensure accurate placement of the induced index changes within the core of the fiber; 2) the intensity diminished so that grating writing above the damage threshold was not reached (for a photosensitive fiber core type I gratings can be written this way but these do not offer any more benefits than using conventional UV writing source).

Unlike the densification gratings, the key mechanism appears to be multiphoton absorption and cascaded impact ionisation triggered by Zener tunneling ionisation [33, 34].

\section{Discussions and conclusions}

Gratings are now readily written into both photosensitive and non-photosensitive structured optical fibers of various sorts using a range of photosensitive mechanism - a specific review of these mechanisms can be found elsewhere [35]. Figure 4 shows the type of fibers into which gratings have been successfully written. Such is the progress that standard processes can be used for hydrogen loading, splicing, and writing [9, 10]. As well, access into the band edge has meant some of the advantages of single material fibers are not compromised by having to add dopants. Even femtosecond lasers have been successfully used to write gratings above the damage threshold. More recently, a particularly good review on novel holographic phase mask writing with femtosecond lasers has become available [36]. By opening up the structured fibers to gratings, a variety of unique applications spanning photonic devices, sensing, diagnostics and lasers has been made available. Much room remains for further understanding and improvements both from a mechanistic perspective and a practical writing perspective. 

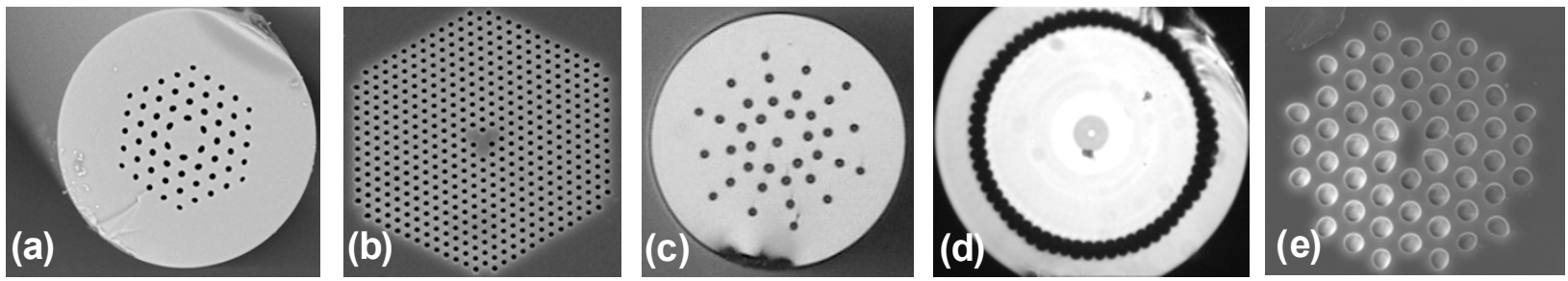

Fig. 4 Typical structured optical fibers into which gratings have been written: (a) low loss $(<4 \mathrm{~dB} / \mathrm{km})$ 4-ring all-silica photonic crystal optical fiber for sensing and components, (b) 12-ring photonic crystal fiber with triangular core and photosensitive, high NA step-index germanosilicate centre for nonlinear applications, (c) simple Fresnel fiber for biodiagnostics, (d) air-clad fiber with $\mathrm{Yb}^{3+}$-doped core for high power fiber lasers, and (e) single-material all silica hi-birefringent fiber for zero temperature dependence sensing applications.

\section{Acknowledgment}

Funding for the work described here was provided by the Australian Research Council (ARC) through Discovery Projects (DP 0879465 \& DP0770692) and Department of Innovation, Industry, Research and Science (DIISR) FrenchAustralia Science Technology (FAST) grant (FR060177) and a DIISR International Science Linkage grant (CG130013).

\section{References}

[1] Bjarklev, J. Broeng, and A. S. Bjarklev, Photonic Crystal Fibers, Netherlands: Kluwer Academic Publishers, 2003.

[2] J. Canning, "Fresnel Optics Inside Optical Fibers," in Photonics Research Developments, New York: Nova Science Publishers, 2008, Chap. 5.

[3] P. Kaiser and H. W. Astle, "Low-loss single-material fibers made from pure fused silica," Bell Syst. Tech. J., vol. 53, no. 6, pp. 1021-1039, 1974.

[4] D. J. DiGiovanni and J. S. Windeler, US Patent, 5,907,652, 1998.

[5] H. Nguyen, P. Domachuk, B. Eggleton, M. Steel, M. Straub, M. Gu, and M. Sumetsky, "A new slant on photonic crystal fibers," Opt. Express, vol. 12, no. 8, pp. 1528-1539, 2004.

[6] C. Martelli, J. Canning, B. Gibson, and S. Huntington, "Cryptography based on Coherent Scattering of Light," in Conference on the Optical Internet/Australian Conference on Optical Fiber Technology, Technical Digest (CD) (Engineers Australia, 2007), paper CWe32, 2007.

[7] H. Sørensen, J. Canning, J. Lægsgaard, K. Hansen, and P. Varming, "Liquid filling of photonic crystal fibers for grating writing," Opt. Comm., vol. 270, no. 2, pp. 207-210, 2007.

[8] N. Groothoff, J. Canning, N. Jovanovic, G. D.
Marshall, and M. J. Withford, "Gratings in Large Diameter Air-Clad Optical Fiber Using a Femtosecond Laser," in Bragg Gratings, Photosensitivity, and Poling in Glass Waveguides, OSA Technical Digest (CD) (Optical Society of America, 2007), paper BWC3, 2007.

[9] N. Groothoff, N. Jovanovic, G. D. Marshall, J. Canning, and M. J. Withford, "Femtosecond Laser Writing of Fiber Bragg Gratings in Large Diameter Air-clad Optical Fiber", Glass Tech.: The European J. of Glass Sci. \& Tech. Part A, vol. 50, no. 1, pp. 75-78, 2009.

[10] H. Sørensen, J. B. Jensen, F. Bruyere, and K. P. Hansen, "Practical hydrogen loading of air silica fibers," presented at Bragg Gratings, Photosensitivity and Poling, Sydney, Australia, July 4-9, 2005.

[11] A. Pohl, K. Cook, and J. Canning, "Bragg grating writing in $\mathrm{H}_{2}$-loaded many-layered $\mathrm{PCF}$ without liquid filling of the holes", presented at Australian Conference on Optical Fiber Technology \& Opto-Electronics and Communications Conference (ACOFT/OECC 08), Darling Harbour, Sydney, 2008.

[12] V. Beugin, L. Bigot, P. Niay, M. Lancry, Y. Quiquempois, M. Douay, G. Mélin, A. Fleureau, S. Lempereur, and L. Gasca, "Efficient Bragg gratings in phosphosilicate and germanosilicate photonic crystal fiber," Appl. Opt., vol. 45, no. 32, pp. 8186-8193, 2006.

[13] K. Cook, A. Pohl, and J. Canning, "Positive and Negative Index Gratings in 10-ring photonic crystal fibers with germanosilicate cores using $193 \mathrm{~nm}$," presented at Australian Conference on Optical Fiber Technology \& Opto-Electronics and Communications Conference (ACOFT/OECC 08), Darling Harbour, Sydney, 2008.

[14] K. Cook, A. Pohl, and J. Canning, "High-temperature type IIa gratings in 12-ring photonic crystal fiber with germanosilicate," J. European Opt. Soc., vol. 3, pp. 08031, 2008.

[15] J. Canning, J. H. Holdsworth, and C. Dewhurst, "Rotational dependence of laser light accessing 
photonic crystal fiber cores from the side," SPIE, vol. 7004, \#70041L-19 $9^{\text {th }}$ International Conf. on Optical Fiber Sensors (OFS 2008), (Ed. D. Sampson, S. Collins, K. Oh, R. Yamauchi Perth), Australia, 2008.

[16] J. Holdsworth, S. Bandyopadhyay, J. Canning, M. Stevenson, and J. de Iuliis, "Transversally illuminating the core of a photonic crystal fibers," presented at Australian Conference on Optical Fiber Technology \& Opto-Electronics and Communications Conference (ACOFT/OECC 08), Darling Harbour, Sydney, 2008.

[17] J. Holdsworth, K. Cook, J. Canning, S. Bandyopadhyay, and M. Stevenson, "Rotationally Variant Grating Writing in Photonic Crystal Fibers," The Open Opt. J., vol. 3, pp. 19-23, 2009.

[18] K. Cook, J. Canning, and J. Holdsworth, "Birefringent gratings in highly nonlinear photonic crystal fibers," presented at Asia-Pacific Optical Fiber Sensors (APOS) Conference, Chengdu, China, 2008.

[19] A. Michie, J. Canning, K. Lyytikäinen, M. Åslund, and J. Digweed, "Temperature independent highly birefringent photonic crystal fiber," Opt. Express, vol. 12, no. 21, pp. 5160-5165, 2004.

[20] A. Michie, J. Canning, I. Bassett, J. Haywood, K. Digweed, A. Lau, D. Scandurra, M. Aslund, B. Ashton, M. Stevenson, and J. Digweed, "Spun elliptically birefringent photonic crystal fiber," Opt. Express, vol. 15, no. 4, pp1811-1816, 2007.

[21] N. Groothoff, J. Canning, K. Lyytikainen, and J. Zagari, "Gratings in air-silica structured fiber," Opt. Lett., vol. 28, no. 4, pp. 233-235, 2003.

[22] J. Canning, N. Groothoff, E. Buckley, T. Ryan, K. Lyytikainen, and J. Digweed, "All-Fiber Photonic Crystal Distributed Bragg Reflector (DBR) Fiber Laser," Opt. Express, vol. 11, no. 17, pp. 1995-2000, 2003.

[23] N. Groothoff, J. Canning, T. Ryan, K. Lyytikainen, and H. Inglis, "Distributed feedback photonic crystal fiber (DFB-PCF) laser," Opt. Express, vol. 13, no. 8, pp. 2924-2930, 2005.

[24] N. Groothoff, C. Martelli, and J. Canning, "A dual wavelength distributed feedback fiber laser," J. Appl. Phys., vol. 103, pp. 013101, 2008.

[25] N. Groothoff, M. Lancry, B. Poumellec, and J. Canning, "193nm Photolytic Mechanism in Er/Al Doped Silica," presented at Australian Conference on Optical Fiber Technology \& Opto-Electronics and Communications Conference (ACOFT/OECC 08), Darling Harbour, Sydney, 2008.
[26] M. Lancry, N. Groothoff, B. Poumellec, and J. Canning, "Photo-induced densification in $\mathrm{Er}^{3+} / \mathrm{Al}$ doped silica preform plates using 193nm laser light," Applied Physics B, vol. 94, no. 4, pp. 589-597, 2009.

[27] C. Martelli, J. Canning, M. Kristensen, and N. Groothoff, "Impact of water and ice $1 \mathrm{~h}$ formation in a photonic crystal fiber grating," Opt. Lett., vol. 31, no. 6, pp. 706-708, 2006.

[28] S. J. Mihailov, D. Grobnic, H. Ding, C.W. Smelser, and J. Broeng, "Femtosecond IR laser fabrication of Bragg gratings in photonic crystal fibers and tapers," IEEE Phot. Tech. Lett., vol. 18, no. 17, pp. 1837-1839, 2006.

[29] C. Smelser, S. Mihailov, and D. Grobnic, "Formation of Type I-IR and Type II-IR gratings with an ultrafast IR laser and a phase mask," Opt. Express, vol. 13, no. 14, pp. 5377-5386, 2005.

[30] E. Bricchi and P. Kazansky, "Extraordinary stability of anisotropic femtosecond direct-written structures embedded in silica glass," Appl. Phys. Lett., vol. 88, pp. 111119, 2006.

[31] B. Poumellec and M. Lancry, "Damage Thresholds in Femtosecond Laser Processing of Silica: A Review," presented at Bragg Gratings, Photosensitivity, and Poling in Glass Waveguides, OSA Technical Digest (CD) (Optical Society of America), 2010.

[32] J. Canning, S. Jackson, M. Åslund, B. Ashton, and K. Lyytikainen, "Air-clad fiber laser with internal grating as feedback element," Electron. Lett., vol. 41, no. 20, pp. 1103-1104, 2005.

[33] M. Lancry, N. Groothoff, S. Guizard, B. Poumellec, P. G. Kazansky, and J. Canning, "Influence of pure silica $\mathrm{OH}$ content on femtosecond laser processing," presented at Proceedings of 7th symposium on $\mathrm{SiO}_{2}$, advanced dielectrics and related devices, Saint-Etienne, France, 2008.

[34] M. Lancry, N. Groothoff, S. Guizard, W. Yang, B. Poumellec, P. G. Kazansky, and J. Canning, "Femtosecond laser direct processing in wet and dry silica glass," J. of Non-Crystalline Sol., vol. 355, no. 18-21, pp. 1057-1061, 2009.

[35] J. Canning, "Fiber Gratings and Devices for Sensors and Lasers," Lasers and Photonics Reviews, vol. 2, no. 4, pp. 275-289, 2008.

[36] S. J. Mihailov, D. Grobnic, C. W. Smelser, P. Lu, R. B. Walker, and H. Ding, "Fiber Bragg grating inscription using infrared femtosecond pulsed lasers," in Trends in Photonics (Ed. J. Canning), 2010, Chap. 4. 